\title{
Dinamika dan Tantangan Pustakawan di Era Globalisasi
}

\author{
Muhamnmad Tawwaf ${ }^{1}$ \\ Univeristas Islam Negeri Sultan Syarif Kasim Riau \\ muh.tawwaf@yahoo.co.id
}

\begin{abstract}
Abstrak
In the various of librarian forums are still intense and interesting to discuss about the competence and professionalism of librarians, this is because of the profession of librarians in this era of globalization is a very strategic profession and received a very wide attention among libraries, especially in the library of universities in terms of Information management. Competence and professionalism for those who hold this profession are a challenge and discussed in the various of librarian forums in the global era. Librarian readiness to face the digital era in meeting the needs of users who are very diverse information by the user cannot be considered normal, As information managers, librarians in the era of information flooding in cyberspace today requires competence and professionalism as the librarian definitions contained in Law no. 43 of 2007 on libraries, that librarian is someone who has competence obtained through education and / or training librarianship and has the duty and responsibility to implement library management and services. Librarians are currently dealing with users who are called "native engine" users who are not separated daily with information technology tools that all want fast, easy and efficient in terms of information accessibility. Information packs that will slowly shift from paper to soft sources into librarian bets to understand and be able to manage and distribute various of information in the data base. The third millennium is an information age that forces librarians to begin switching paradigms and repositioning their roles over the years. The independence and productivity of librarians to change and become agents of change for themselves and society, and being able to position themselves as information managers for the community is imperative. The competence of librarians in terms of online research skills
\end{abstract}

\footnotetext{
${ }^{1}$ Pustakawan Madya Pada Perpustakaan Pusat UIN Suska Riau
} 
should also be held to anticipate the needs of users, especially researchers who are in dire need of various sources that have been packaged in digital form, as the researcher consumption must be obtained from E'Journal and publication also through open journal system or scopus is a challenge for librarians as information manager. One of the aims of this paper is to publicize and reveal what librarians need to anticipate in the era of information flooding in the face of technological developments and the current changing phenomenon, so librarians must be able to uncover what is changing and what should to do. The Demands of the needs of library users increasingly diverse in this information technology era, the library needs to prepare a professional librarian and competent in their fields which, according to some librarian research results have not been encouraging.

Keywords: Librarian, Global Era, Competence, Professionalism

\begin{abstract}
Abtrak
Di berbagai forum kepustakawanan saat ini masih intens dan menarik untuk membicarakan tentang kompetensi dan profesionalisme pustakawan, hal ini disebabkan karena profesi pustakawan di era globalisasi ini merupakan profesi yang sangat strategis dan mendapat perhatian yang sangat luas di kalangan perpustakaan, khususnya pada perpustakaan perguruan tinggi dalam hal pengelolaan informasi. Kompetensi dan profesionalime bagi yang menyandang profesi ini merupakan sebuah tantangan dan menjadi bahan diskusi di berbagai forum kepustakawanan di era global. Kesiapan pustakawan menghadapi era digital dalam memenuhi kebutuhan pengguna yang sangat beragam akan informasi oleh pengguna tidak bisa dianggap biasa, Sebagai pengelola informasi, pustakawan di era banjir informasi di dunia maya saat ini menuntut kompetensi dan profesionalisme sebagaimana definis pustakawan yang tertuang di dalam UU No. 43 Tahun 2007 tentang perpustakaan, bahwa pustakawan adalah seseorang yang memiliki kompetensi yang diperoleh melalui pendidikan dan / atau pelatihan kepustakawanan serta mempunyai tugas dan tanggung jawab untuk melaksanakan pengelolaan dan pelayanan perpustakaan. Pustakawan saat ini berhadapan dengan pengguna yang disebut "native engine" pengguna yang kesehariannya tidak lepas dengan alat-alat teknologi informasi yang serba ingin cepat, mudah dan efisien dalam hal aksesbilitas informasi. Kemasan informasi yang lambat laun akan bergeser dari kertas ke soft sources menjadi taruhan pustakawan untuk memahamai dan mampu mengelola dan mendistribusikan berbagai informasi dalam database. Abad millenium ke tiga merupakan abad informasi yang memaksa pustakawan untuk mulai beralih paradigma dan melakukan reposisi terhadap perannya selama
\end{abstract}


ini. Kemandirian dan Produktivitas pustakawan untuk berubah dan menjadi agen perubahan bagi diri dan masyarakat, serta mampu menempatkan dirinya sebagai manajer informasi bagi masyarakat adalah keharusan. Kompetensi pustakawan dalam hal online research skill juga harus dimiliki untuk mengantisipasi kebutuhan pengguna terutama peneliti yang sangat membutuhkan berbagai macam sumber yang sudah dikemas dalam bentuk digital, sebagai konsumsi peneliti yang mesti diperoleh dari E'Journal dan publikasinya juga melalui open journal system atau scopus adalah merupakan tantangan tersendiri bagi pustakawan sebagai information manager. Salah satu tujuan dari tulisan ini adalah untuk mempublikasikan dan mengungkap hal-hal yang perlu diantisipasi oleh pustakawan pada era banjir informasi yang berhadapan langsung dengan perkembangan teknologi serta fenomena perubahan yang yang terjadi saat ini, sehingga pustakawan harus bisa mengungkap apa yang berubah dan apa yang seharusnya dilakukan. Tuntutan kebutuhan pengguna perpustakaan yang semakin beragam pada era teknologi informasi ini, perpustakaan perlu mempersiapkan pustakawan yang profesional dan kompeten dibidangnya yang menurut beberapa hasil penelitian kepustakawan belum menggembirakan.

Kata kunci: Pustakawan, Era Global, Kompetensi, profesinalisme

\section{Pendahuluan}

Pada saat ini perguruan tinggi Indonesia sudah menghadapi berbagai tantangan besar yang perlu di respons dengan bijaksana. Globalisasi dalam segala bidang dan revolusi teknologi informasi adalah dua kekuatan besar yang amat mempengaruhi dunia penguruan tinggi Indonesia. Kalau lembaga pendidikan tinggi nasional tidak mampu merespons tantangan globalisasi ini dengan adaptif, diperkirakan lembaga tersebut akan tidak mampu mempertahankan eksistensinya di masyarakat dan secara pelan tetapi pasti akan mengalami marjinalisasi . hal ini dapat dilihat perkembangan perguruan tinggi melalui ranking yang dikeluarkan oleh beberapa lembaga survei.

Alam pendidikan tinggi yang menganut faham universialisme ilmu pengetahuan dan teknologi sebenarnya selalu mempertimbangan bahwa masyarakat pendidikan Indonesia adalah bagian dari masyarakat global. Proses seperti ini disebut globalitas yang sudah berlangsung sejak lama dalam dunia pendidikan maupun dalam perdagangan intenasional. Tetapi dalam 
perkembangan yang terjadi sejak 1980an globalisasi berkembang menjadi "the process through which sovereign national states are criss-crossed and undermined by transnational actors - governments or MNCs - with varying prospects of power, orientations, identitities, and networks". Dalam proses globalisasi tersebut, dua kekuatan yang amat menentukan adalah kemajuan atau bahkan revolusi teknologi khususnya dalam teknologi informasi dan bioteknologi yang dikuasai oleh perusahaan-perusahan yang memiliki menugasai modal finansial dan intelektual. Restrukturisasi sosial-ekonomi yang terjadi di negara-negara maju pada kurun waktu 1980an terjadi karena didorong oleh dua kekuatan besar yakni kemajuan teknologi informasi dan keputusan perusahaan yang menguasai modal besar. Pada kondisi seperti ini wilayah suatu negara berdaulat akan mengalami perubahan mendasar dalam superstruktur dan substrukturnya.

Menurut Effendi (2005) dalam Surachman (2014:3) menyatakan pada era globalisasi akan ada Liberalisasi 12 sektor jasa seperti dalam bidang pendidikan, teknologi informasi dan komunikasi, pendidikan sepanjang hayat, dan lain-lain yang menjadi agenda WTO melalui apa yang disebut dengan General Agreement onTrade in Services (GATS) mau tidak mau juga akanmempengaruhi bidang perpustakaan dan informasi. Surachman (2014) juga menjelaskan ketika negara-negaradi luar Asia Tenggara masuk dan ikut bersaing dalam jasa pendidikan, teknologi informasi dan komunikasi, dan pendidikan sepanjang hayat di Asia Tenggara,maka pelaku pendidikan juga harus mampu meningkatkan segala kemampuan dan fasilitas agar mampu bersaing. Sedangkan dalam lingkup ASEAN telah disepakati adanya AFTA (Asean Free Trade Agreement) yang merupakan bagian dari agenda pembentukan Masyarakat Ekonomi Asean (MEA) atau Asean Economics Community yang akan berlaku secara mutlak pada tahun $2015 .^{2}$

Sebagai lembaga akademik yang secara bertugas mengembangkan ilmu pengetahuan dan teknologi, perguruan tinggi adalah lembaga yang paling merasakan tuntutan sosial untuk perubahan global tersebut. Dunia

${ }^{2}$ Kristina. Transformasi Pustakawan Dalam Era Globalisasi, http://library. stiesia.ac.id /assets/ lib-doc/b, diakses pada tanggal 28 April 2017. Jam $10.00 \mathrm{Wib}$ 
usaha, pemerintah dan masyarakat yang memerlukan ilmu pengetahuan baru yang berbasis teknologi informasi, bioteknologi serta ilmu-ilmu multidisiplin lainnya akan menuntut perguruan tinggi untuk memenuhi kebutuhan mereka akan ilmu pengetahuan dan teknologi yang lebih tinggi. Globalisasi dalam segala bidang yang sedang berlangsung dengan cepat pada beberapa dekade ke depan, di satu fihak akan memberikan kesempatan yang amat besar kepada perguruan tinggi untuk memberikan pelayanan ilmu pengetahuan dan teknologi baik kepada pemerintah, masyakarat mau pun kepada dunia usaha. Tetapi kalau perguruan tinggi terlalu terjerumus pada kegiatan tersebut, peranan perguruan tinggi selama ini yang hampir monopolisitik dalam pengembangan ilmu pasti akan mengalami perubahan drastis. Yang tidak kalah pentingnya untuk selalu diperhatikan adalah peranan perguruan tinggi sebagai lembaga menghasilkan calon pemimpin bangsa yang berwawasan intelektual, bermoral dan berbudaya demokratis. Kalau perguruan tinggi terlalu terjebak dalam arus globalisasi yang merupakan suatu proses yang nirdemokratis, secara pasti perguruan tinggi akan tidak mampu melaksanakan salah satu tugas utamanya tersebut.

Globalisasi dalam segala aspek ini telah membawa implikasi positif maupun negatif yang sangat besar pada dunia perguruan tinggi baik dalam pembiayaan, populasi calon mahasiswa serta perubahan peranan perguruan tinggi. Perubahan ini harus direspons dengan baik oleh perguruan tinggi agar dapat tetap memainkan peranan pentingnya dalam tataran masyarakat global.

\section{Eksistensi Perpustakaan di Perguruan Tinggi}

Semakin pesatnya Perkembangan Teknologi informasi dan Komunikasi (TIK) dewasa ini sangat membantu kebutuhan masyarakat akademisi untuk memenuhi kebutuhan informasi mereka. Hal ini lah yang berdampak pada Perpustakaan Perguruan Tinggi, perpustakaan mau tidak mau suka atau tidak suka harus melakukan perubahan yang sangat mendasar demi memenuhi tuntutan dari pemustakanya yang berasal dari lingkungan akademisi ataupun pemustaka lainnya. Peran perpustakaan sebagai penyedia informasi ditandai dengan kemudahan bagi orang untuk mengakses berbagai 
informasi dengan tidak terbatas oleh ruang dan waktu.

Era globalisasi informasi juga ditandai dengan hadirnya teknologi informasi yang merambah di berbagai aspek kehidupan, tak pelak juga diperpustakaan. Tantangan dan tuntutan baru di era global dengan teknologiinformasi khususnya bagi para pekerja informasi dan lembaga informasiseperti perpustakaan adalah bagaimana perpustakaan menyalurkan informasi dengan cepat, tepat dan global ${ }^{3}$. Perpustakaan sebagai salah satu media penampung dan penyedia informasi yang keberadaannya sangat penting didunia informasi, mau tidak mau harus juga berpikir mengenai bentuk yang tepat untuk menanggapi tantangan ini. Banyak peran yang masih bisa dimainkan oleh lembaga perpustakaan di era informasi global. Perpustakaan memang harus menyesuaikan dengan tuntutan itu.

Perpustakaan perlu mengivestasikan sejumlah besar biaya untuk membangun infrastruktur global terkait dengan teknologi informasi. Membeli komputer, printer, scanner, terhubung ke jaringan internet dan intranet merupakan salah satu bukti bentuk fisik bahwa perpustakaan juga mengarah pada trend informasi global. Disamping penyediaan perangkat keras, dibutuhkan pula dukungan perangkat lunak seperti software software yang mendukung implementasi teknologi informasi di perpustakaan. Software yang demikian banyak di pasaran, tentu juga membutuhkan kajian yang cukup mendalam, akan memilih software yang seperti apa yang sesuai dengan kebutuhan perpustakaan masing masing.

Selain itu dukungan kualitas sumberdaya manusia juga menentukan keberhasilan perpustakaan dalam implementasi teknologi informasi untuk menjawab tantangan global. Kemampuan dan daya saing perpustakaan yang sudah membangun perangkat teknologi informasi sangat bergantung kepada kualitas sumber daya manusianya. Dibutuhkan berbagai pelatihan agar tenaga/staf di perpustakaan tidak dikatakan gagap teknologi alias tidak bisa mengoperasikan peralatan teknologi informasi. Kahadiran perangkat teknologi tidak akan mematikan tugas dan fungsi

${ }^{3}$ American Library Association. Libraries, Literacy \& Learning in the 21st Century. American Libraries, 2005 
perpustakaan secara pokok. Karena informasi yang melimpah di era global juga perlu untuk diatur, dan dikelola, dipilih, dipilah, dikenali dan didistribusikan kepada orang yang sesuai dengan isi informasi tersebut. Tugas perpustakaan akan mengatur berbagai macam nformasi, mengolah dan mendistribusikan kepada pihak pihak yang sesuai dengan informasi tersebut.

Ada beberapa peran yang masih diperlukan dan perpustakaan masih mampu untuk menanganinya antara lain :

1. Perpustakaan sebagai mitra dari berbagai kalangan masyarakat yang membutuhkan informasi yang sifatnya tercetak dan tidak membutuhkan sentuhan teknologi tinggi.

2. Perpustakaan masih punya peran sebagai salah satu tempat untuk membaca dan belajar tanpa harus susah payah untuk membawa perangkat teknologi.

3. Teknologi informasi di perpustakaan sebagai alat bantu bagi pengguna untuk menemukan sumber sumber lain sebagai pelengkap dari sebuah karya.

4. Perpustakaan masih bertugas untuk mengorganisasikan informasi tesebut agar memiliki nilai yang lebih baik bagi masyarakat pemustakanya.

5. Perpustakaan perlu untuk memilih informasi informasi yang tidak perlu, karena salah satunya tidak adanya kejelasan dari pencipta informasi yang tersedia di dunia maya.

6. Perpustakaan masih menjadi tempat yang menyenangkan untuk saling bertemu, berdiskusi, dan bersosialisasi antar penggunanya.

Kemajuan teknologi informasi dewasa ini, perlu kita sikapi dengan pikiranyang bijak dan jernih. Kemajuan teknologi informasi disatu sisi membawa perubahan besar yang baik bagi masyarakat dengan kemampuan mengoperasikan komputer, menelusur informasi yang sifatnya on-line, berkomunikasi secara on line danjuga lebih murahnya tariff tertentu misalnya dalam surat menyurat. Disisilain, yang harus kita cermati adalah bahwa negara Indonesia dengan penduduk yang demikian besar, menjadi incaran berbagai bangsa lain untuk memasarkan produknya, baik yang berkualitas 
maupun yang kita anggap sebagai sampah. Oleh karena itu kita perlu juga melakukan saringan terhadap informasi yang kita terima, apakah informasi itu dapat dipertangungjawabkan atau malah kita akan disesatkan oleh informasi yangkita dapat dengan tidak kita ketahui siapa yang bertanggung jawab dibalik informasi tersebut.

Di era globalisasi saat ini, membuat masyarakat akademisi menuntut adanya akses informasi yang cepat, mudah, tepat, akurat, up to date serta murah. Apabila hal diatas tidak diantisipasi oleh perpustakaan tersebut, maka sama halnya dengan perpustakaan mengalami kelumpuhan yang lambat laun akan ditinggalkan oleh masyarakat penggunanya.

Oleh karena itu, jika kita membahas mengenai perpustakaan dalam dimensi era globlisasi maka tentunya hal ini akan mempunyai berbagai penafsiran yang bermacam-macam. Salah satu dampaknya adalah bahwa terjadinya perubahan dalam domain Kelembagaan perpustakaan tersebut. Hal ini terkait dengan perubahan dan kecenderungan perilaku masyarakat pemakai perpustakaannya. Berbagai perubahan yang nampak antara lain: ${ }^{4}$ 1. Digital native, generasi millenial, generasi internet, dan gadged technology.

2. Kegiatan pengelola perpustakaan dan pustakawan.

3. Efektivitas reputasi, yang meliputi image dan branding perpustakaan.

4. Manajemen perubahan organisasi perpustakaan.

5. Layanan berbasis Teknologi Informasi dan Komunikasi (TIK).

\section{Kesiapan Pustakawan di Era Globalisasi}

Dalam era globalisasi dan ditengah gempuran kecanggihan teknologi informasi pekerjaan seorang pustakawan tidak hanya bersifat teknis tetapi pustakawan dituntut untuk dapat berpikir inovatif, kreatif serta cerdas karena mereka adalah para manajer informasi dan pengetahuan dan "the thinking search engine" yang lebih cerdas dalam menyediakan informasi dan pengetahuan yang dibutuhkan oleh pemustaka yang mana pada era

${ }^{4}$ Endang Fatmawati. Perpustakaan dalam Dimensi Pos Modernisme, ttp://journal.unair.ac.id/ download-fullpapers-palimf5c797a27cfull.pdf. diakses pada tanggal 2 Mei 2017 
informasi, informasi dapat di akses dengan cepat dan mudah melalui search engine manapun tetapi tanpa adanya tahap seleksi. Selain itu pustakawan juga bukan hanya orang yang menunggu pemustaka untuk datang ke perpustakaan melainkan pustakawanyang mendatangi pemustaka untuk datang ke perpustakaan (bring users In) melalui penyediaan fasiitas yang ada.

Menurut Mary Lynn Rice-Lively dalam (Naibaho, 2014) seorang pustakawan akademik harus memiliki kemampuan sebagai berikut :

1. Continuous improvement. Pustakawan harus terus melakukan perbaikan yang berkesinambungan agar dapat mengembangkan dan memperbaiki profesionalitas diri yang bertujuan mendapatkan hasil terbaik dari usaha tersebut, yang memberikan solusi terbaik bagi masalah yang ada, yang hasilnya dapat bertahan dan bahan berkembang menjadi lebih baik lagi.

2. Asertif. Kemampuan seseorang untuk berperilaku secara jujur, terbuka, tegas dan langsung pada tujuan. Maksudnya pustakawan harus dapat berperilaku jujur, terbuka dan tegas ketika berkenaan dengan pemberian layanan pada pemustaka.

3. Information literate. Pustakawan harus dapat meakukan penelususran informasi yang tepat guna bagi pemustakanya serta pustakawan juga dapat memberikan materi literasi informasi kepada pemustaka agar ia dapat menelusur informasi secara mandiri.

4. Paham sistem akademik. Pustakawan harus mampu memberikan informasi akademik bagi pemustaka yang membutuhkan karena pustakawan akan menjadi pusat informasi bagi seluruh civitas akademika.

5. Mengerti proses penelitian. Pustakawan di era informasi dituntut harus paham akan proses penelitian karena selain dituntut untuk melakukan penelitian dalam lingkungannya pustakawan juga dapat memberikan bimbingan penelitian bagi pemustaka yang mendukung fungsi perpustakaan sebagai research centre.

6. Percaya diri. Pustakawan harus percaya diri akan profesinya dan tugasnya, sehingga dengan kepercayaan diri tesebut pustakawan memiliki kemampuan yang baik dalam memberikan layanan informasi bagi pemustaka. 


\section{Kualifikasi Pustakawan}

Berdasarkan tinjauan kualifikasi dari beberapa pendapat dan trend dalam era digital sebagaimana yang telah dipaparkan di atas, penulis berpendapat bahwa pustakawan di era digital ini antara lain harus memiliki kualifikasi sebagai berikut : ${ }^{5}$

a. Kemampuan Profesional.

Kemampuan profesional adalah kemampuan profesi yang harus dimiliki setiap pustakawan dan professional informasi lainnya dalam menjalankan perannya di era digital.

\section{b. Kemampuan Umum}

Kemampuan umum bagi professional informasi mencakup kemampuan dibidang manajemen dan organisasi informasi serta penggunaan teknologi informasi. Secara spesifik kemampuan umum ini antara lain :

1) Kemampuan menjadikan ruang digital sebagai ruang pembelajaran virtual yang efektif

2) Kemampuan konseptual dan teknis dalam teknologi informasi dan manajemeninformasi (manajemen pengetahuan) sesuai dengan tingakatan tanggung jawab pekerjaan.

3) Kemampuan berkomunikasi, terutama komunikasi interpersonal dan komunikasi antarbudaya serta komunikasi bermedia komputer/ internet mengingat dunia digital menjangkau dunia tanpa batas dengan beragam latar belakang budaya para pengakses layanan informasi.

4) Memahami etika dunia maya dan UU ITE termasuk pendistribusian informasi karena akan selalu berhubungan dengan hak cipta atau hak akan kekayaan intelektual dari sebuah informasi yang ditawarkan.

5) Kemampuan menulis karena pustakawan digital akan selalu berhadapan dengan update data setiap saat, termasuk reportase real-time.

6) Kemampuan bekerja sama. Dunia digital membuka peluang kolaborasi yang lebih luas baik antar perpustakaan maupun antar

${ }^{5}$ Nuning Kurniasih. "Kualifikasi Pustakawan Di Era Digital”. Makalah disampaikan pada Semiloka Kepustakawanan ISIIPI, 2015 
pustakawan.

7) Kemampuan bahasa, baik bahasa ibu maupun bahasa internasional.

8) Kemampuan dalam organisasi dan distribusi informasi.

\section{c. Kemampuan Khusus}

Kemampuan khusus akan sangat beragam karena berkaitan dengan tempat pustakawan bekerja. Misalnya kemampuan Bahasa Asing selain Bahasa Inggris atau kemampuan analisa sesuai dengan bidang kajian yang ditanganinya.

\section{d. Kemampuan Personal}

Kemampuan personal mencakup kemapuan yang seharusnya melekat pada diri pustakawan atau sering disebut sebagai soft skills seseorang. Kemampuan personal antara lain mencakup kemampuan analisa, kemampuan bernegosiasi, kemampuan beradaptasi, bersosialisasi, bekerja sama, kreativitas dan motivasi diri untuk terus belajar.

Pustakawan harus memacu diri sehingga tidak menjadi pononton di rumah sendiri atau tergusur dari lembaganya. Kompetensi pustakawan Indonesia bila dibandingkan dengan negara-negara ASEAN tidak bisa dipungkiri bahwa mereka lebih baik dari pustakawan Indonesia. Berdasarkan pengalaman penulis yang sudah berkunjung ke 4 perpustakaan Negara ASEAN (Malaysia, Vietnam, Singapura dan Thailand), 5 negara daratan Eropah (Holland, France, Swiss, German, and Belgium), dan beberapa perpustakaan di negera lain seperti Hong Kong, Jepang Timur Tengah dan North America tepatanya CANADA dari berbagai forum pertemuan yang dihadiri, hanya sebagian kecil pustakawan Indonesia yang mampu berpartisipasi dalam kegiatan kepustakawan Asean (Asean Librarianship) apalagi tingkat dunia seperti "World Library and Information Congress, IFLA General Conference and Assembly yang diadakan setiap tahun di berbagai belahan Negara di dunia. ${ }^{6}$

${ }^{6}$ Muhammad Tawwaf. "Kesiapan Pustakawan Menghadapi MEA”. Jurnal Perpustakaan UIN Ar-Raniry Aceh, 2016 


\section{Penutup}

Berdasarkan penjelasan diatas dapat disimpulkan bahwa pada era globalisasi, pustakawan telah mengalami evolusi, dimana kompetensi dan kualifikasi pustakawan yang telah disebutkan di atas diharapkan mampu membawa pustakawan memenangkan persaingan di era global yang juga sering disebut era digital. Era digital sendiri merupakan sebuah proses untuk menjamin kelancaran pencapaian tujuan akhir secara bertahap, segala sesuatunya perlu dipersiapkan secara matang dalam menyediakan kebutuhan pemustaka. Dalam menghadap perubahan setiap waktu, pustakawan dituntut untuk memiliki kompetensi yang bersifat profesional dan personal serta survival skill dalam menghadapi tantangan dalam ea global. Untuk eksis dalam dunia persaingan global pustakawan harus memiliki karakteristik yang antara lain adalah menerapkan prinsip long life learning dalam hidupnya, memiliki sikap tegas, berpikir kreatif dan inovatif, memiliki kepercayaan diri yang tinggi akan kemampuan dan bangga terhadap profesinya. Pustakawan diharapakan memiliki kemampuan berbahasa yang baik sebagai alat komunikasi dengan menguasai bahasa internasional yaitu bahasa Indonesia, bahasa Inggris dan bahasa asing lainnya, sehingga bisa dan mampu berperan dalam forum kepustakawan baik skala nasional, ragional, internasional, bahkan tiangkat dunia sekalipun, sehingga pustakawan tidak hanya terlena dan asyik dengan pekerjaan teknisnya saja meskipun itu tidak bisa dihindari.

Sebagai akhir makalah ini ada sebuah kutipan dari Carl Sagan dalam A.B. Credaro :

"The library connects us with the insight and knowledge, painfully extracted from Nature, of the greatest minds that ever were, with the best teachers, drawn from the entire planet and from all our history, to instruct us without tiring, and to inspire us to make our own contribution to the collective knowledge of the human species. I think the health of our civilization, the depth of our awareness about the underpinnings of our culture and our concern for the future can all be tested by how well we support our libraries." (Credaro, 2002). 


\section{Daftar Pustaka}

American Library Association. Libraries, Literacy \& Learning in the 21st Century. American Libraries, 2005

Dupuis, J. \& Ryan, Bridging The Two Cultures: A Collaborative Spproach To Managing Electric Resources. Issues In Science And Technological Librarianship, Spring, 2002

Endang Fatmawati. Perpustakaan dalam Dimensi Pos Modernisme, ttp:// journal.unair.ac.id/download-fullpapers-palimf5c797a27cfull.pdf. diakses pada tanggal 10 Mei 2017

Kristina. Transformasi Pustakawan Dalam Era Globalisasi, http://library. stiesia.ac.id /assets/lib-doc/b, diakses pada tanggal 9 Mei 2017. Jam $10.00 \mathrm{Wib}$

Muhammad Tawwaf. “Kesiapan Pustakawan Menghadapi MEA”. Jurnal Perpustakaan UIN Ar-Raniry Aceh, 2016.

Naibaho, Kalarensi.. Transformasi Pustakawan: Arsiparis dalam Menjawab Tantangan Global..Makalah yang disampaikan pada Temu Karya Fungsional Pustakawan; Arsiparis Tahun 2014/oleh BadanPerpustakaan dan Kearsipan Provinsi Jawaa Timur di Royal Tretes Pasuruan.

Nuning Kurniasih. "Kualifikasi Pustakawan di Era Digital". Makalah disampaikan pada Semiloka Kepustakawanan ISIIPI, 2015 